\title{
Tsunami disaster assessment in the southwestern Pacific countries due to giant earthquakes near Japan
}

\author{
T. Takahashi ${ }^{1}$, S. Koshimura ${ }^{2}$, K. Harada ${ }^{3}$, S. Suzuki ${ }^{4}$, \\ Y. Okumura ${ }^{5} \&$ Y. Kawata ${ }^{4}$ \\ ${ }^{I}$ Department of Civil and Environmental Engineering, \\ Faculty of Engineering and Resource Science, Akita University, Japan \\ ${ }^{2}$ Disaster Control Research Center, Graduate School of Engineering, \\ Tohoku University, Japan \\ ${ }^{3}$ Department of Civil and Environmental Engineering, \\ School of Engineering, Saitama University, Japan. \\ ${ }^{4}$ Research Center for Disaster Reduction System, \\ Disaster Prevention Research Institute, Kyoto University, Japan \\ ${ }^{5}$ Disaster Reduction and Human Renovation Institution, Japan
}

\begin{abstract}
The southwestern Pacific Ocean is prone to significant tsunami risk due to giant earthquakes generated near Japan. In this study, two huge tsunamis in the Japan Trench and the Nankai Trough were assumed. They have been called the Sanriku Earthquake Tsunami and the Tonankai-Nankai Earthquake Tsunami. To check the uncertainty of the tsunami model, four more models that intensify the dislocations of half of the tsunami sources were assessed. The computed tsunami energy distributions show that the Sanriku Tsunami propagates mainly toward the central Pacific Ocean and has little effect on the southwestern Pacific countries. On the other hand, the tsunami in the Nankai Trough propagates mainly toward the southwestern Pacific Ocean because of the Mariana Trench. In many cities, the water level exceeds $50 \mathrm{~cm}$. Further, there are some observation stations along the path of the tsunami propagation and they might be useful for a far field tsunami warning system in this region.
\end{abstract}

Keywords: far field tsunami warning, Japan Trench, Nankai Trough, tide gauge, $D A R T$. 


\section{Introduction}

There are some subductions around Japan. In particular along the Nankai Trough and the Japan Trench shown in figure 1, seismic activities are very high. Many earthquakes and tsunamis have occurred there. The giant tsunamis have caused terrible damage to Japan repeatedly. Nowadays, the tsunami hazard assessments have been carried out and some disaster measures are established in Japan and the Japanese mitigation system against tsunamis has been improving.

The giant tsunamis, however, can propagate in the Pacific Ocean. They attack not only Japan but also many countries in the Pacific Ocean. In particular, the southwestern Pacific countries are supposed to have large tsunami risk, because there is the Mariana Trench between Japan and the region (figure 1). The hazard assessment of the giant tsunamis generated near Japan is required in these countries. Japan can contribute the assessment because much information about the earthquakes has been obtained and the tsunami modeling around Japan has been investigated well.

In this study, the numerical experiment for giant tsunamis near Japan was conducted and the effect of the tsunamis on the countries in the southwestern Pacific Ocean was assessed. Furthermore, the validity of some observation stations to the far field tsunami warning system in this region was also evaluated.

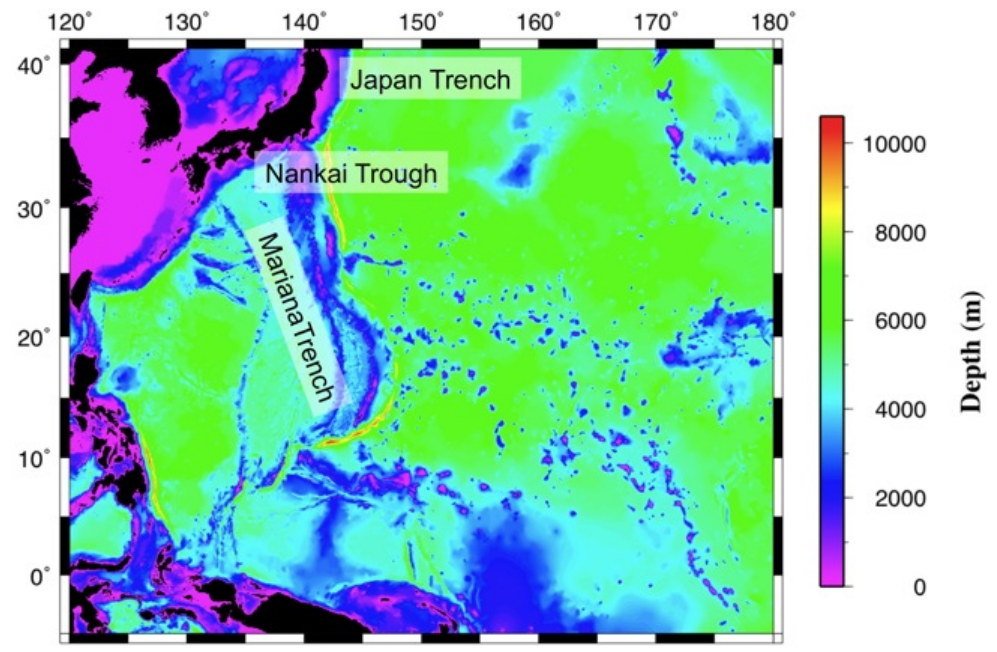

Figure 1: The bathymetry in computational domain.

\section{Methodology}

\subsection{Conditions of numerical experiment}

The linear long wave theory on the spherical coordinate system [1] was used as the governing equation to simulate tsunami propagation. 


$$
\begin{aligned}
& \frac{\partial \eta}{\partial t}+\frac{1}{R \cos \theta}\left(\frac{\partial M}{\partial \lambda}+\frac{\partial N \cos \theta}{\partial \theta}\right)=0 \\
& \frac{\partial M}{\partial t}+\frac{g h}{R \cos \theta} \frac{\partial \eta}{\partial \lambda}=f N \\
& \frac{\partial N}{\partial}+\frac{g h}{R} \frac{\partial \eta}{\partial \theta}=-f M
\end{aligned}
$$

where $\lambda$ and $\theta$ correspond to longitude and latitude, $R$ is the radius of the earth, $t$ is time, $\eta$ is the water level, $h$ is the still water depth, $M$ and $N$ are discharge fluxes in $\lambda$ and $\theta$ directions, $g$ is the gravitational acceleration and $f$ is the Coriolis coefficient. As the numerical scheme, the leap-frog scheme with a staggered grid was adapted. The boundary conditions were the vertical wall (perfect reflection condition) at the shoreline and the open boundary (radiation condition). The spatial and temporal grid sizes were 1 arc minute and 4 seconds. The tsunami propagation of 12 hours in real time was simulated.

The computational domain was $\left(5^{\circ} \mathrm{S}, 120^{\circ} \mathrm{E}\right)$ to $\left(41^{\circ} \mathrm{N}, 180^{\circ} \mathrm{E}\right)$. Figure 1 shows bathymetry in this domain. This bathymetry model was extracted from GEBCO (General Bathymetric Chart of the Oceans) 1 min grid data [2] and the minimum water depth was configured as 10 meters. The maximum water depth is about 10,577 meters in this domain. There is the Mariana trench that could guide the tsunami energy toward the southwestern Pacific countries.

This computation output the maximum water level distribution, arrival time of tsunami propagation and time series of water level at 24 points. As the output points, 12 cities of each country shown in figure 2(a) were selected because of high population densities or high economic activities. Furthermore, 5 tide gauges and 7 DART buoys [3] shown in figure 2(b) were also selected. The water levels at output points were converted into values at the minimum depth by the Green's Law.

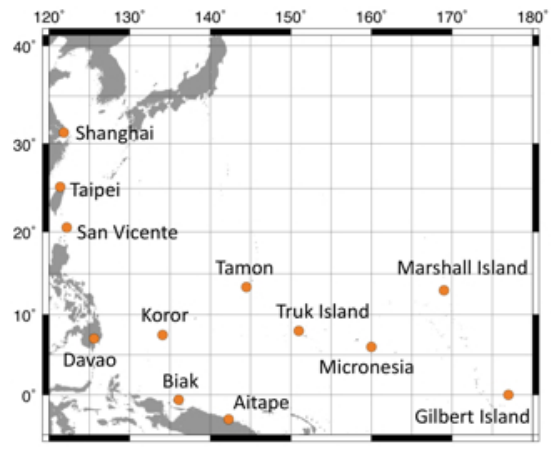

(a) The main cities

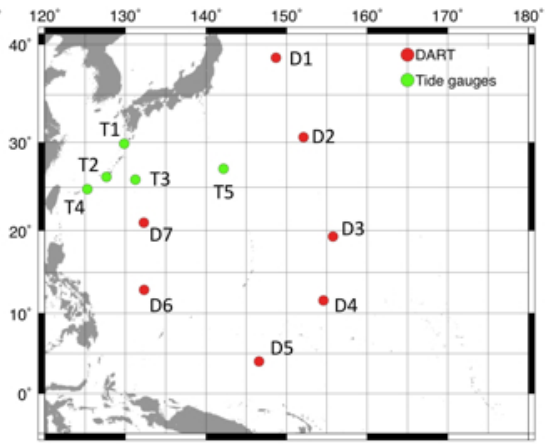

(b) The observation stations

Figure 2: Output points of computation. 


\subsection{Tsunami sources}

The tsunami source was used as an initial condition in the tsunami numerical experiment. In this study, two giant tsunamis in the Japan Trench and the Nankai Trough were assumed. They are called as the Sanriku Earthquake Tsunami and the Tonankai-Nankai Earthquake Tsunami. Their tsunami sources have been provided by the Japanese government $[4,5]$.

Figure 3 shows a tsunami source of the Sanriku Earthquake Tsunami (model $\mathrm{SO}$ ). The moment magnitude was 8.6 and it was very big earthquake. However, no one can predict the absolute same tsunami will occur in future. The uncertainty of tsunami model had to be considered. Then, further two more models SN and SS were also assumed (figure 3). In the two models, the tsunami source of original model (SO) was divided into a northern half and a southern half areas. The model SN intensified dislocation in the northern half area and reduced in the southern half area. The model SS had contrary dislocation to the model SS.

Figure 4 shows a tsunami source of the Tonankai-Nankai Earthquake Tsunami (model NO). The moment magnitude was 8.5. To consider the uncertainty of tsunami model in the same way as the case of the Sanriku Earthquake Tsunami, the models NE and NW were also assumed shown in figure 4. The tsunami source of original model (NO) was divided into a western half and an eastern half areas. The model NE intensified dislocation in the eastern half area and reduced in the western half area. The model NW had contrary dislocation to the model NE.

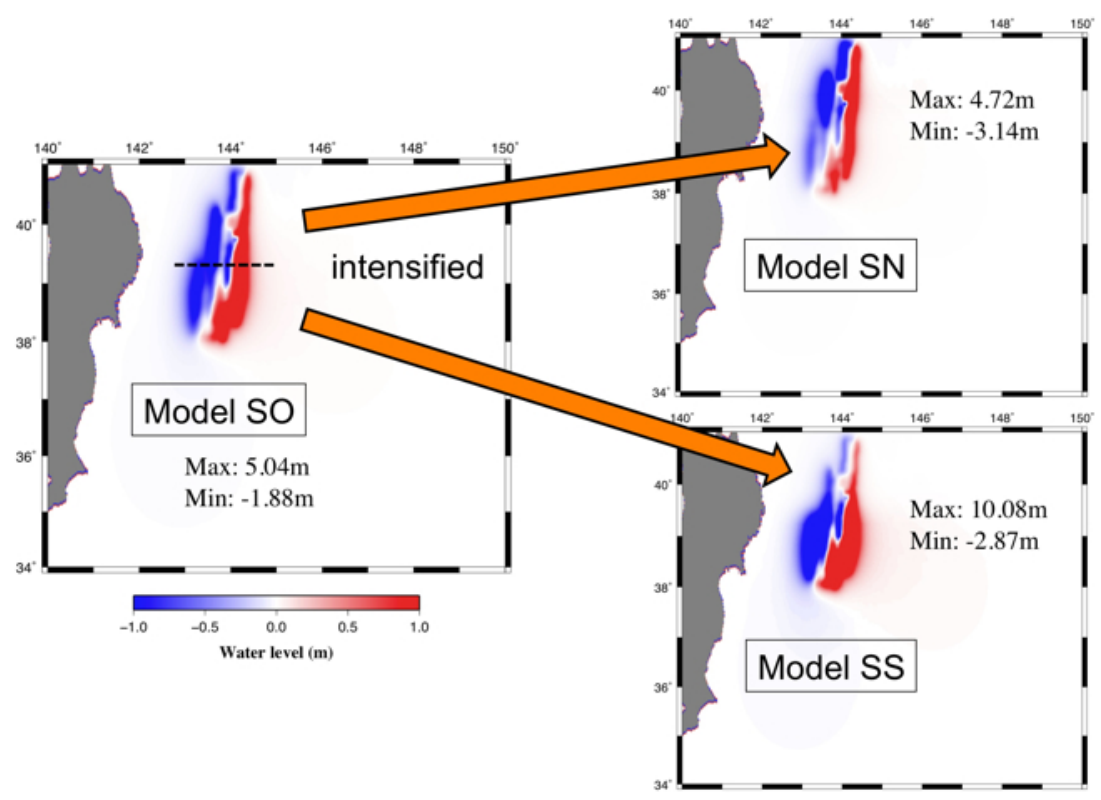

Figure 3: The tsunami sources of the Sanriku Earthquake Tsunami. 


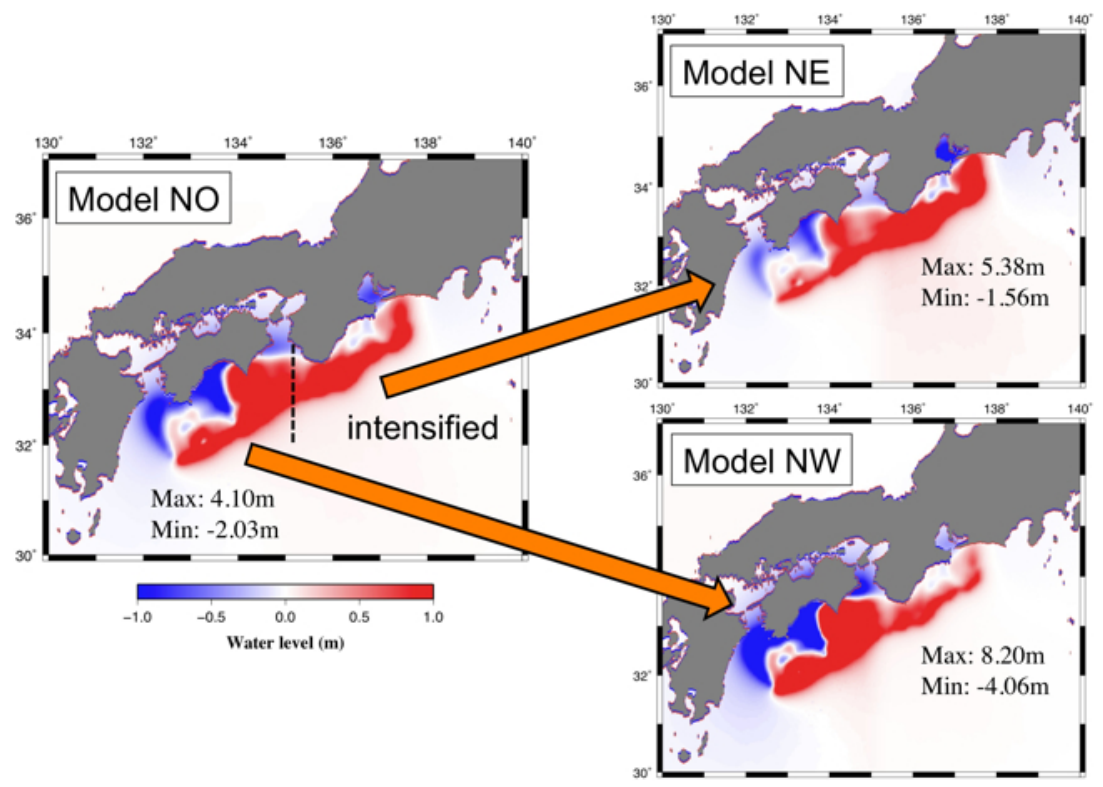

Figure 4: The tsunami sources of the Tonankai-Nankai Earthquake Tsunami.

\section{Computational results}

\subsection{The Sanriku Earthquake Tsunami}

The computed tsunami energy distributions and propagation time distributions of models SO, SN and SE are shown in figures 5 and 6 . The tsunamis propagate in two directions toward the central Pacific Ocean and toward the southwestern Pacific Ocean. The large tsunami energy of the Sanriku Earthquake Tsunami propagates toward the central Pacific Ocean such as Hawaii. This direction is dominant. On the other hand, along the second direction, the tsunami energy is small compared to the first one. The Sanriku Tsunamis arrive in the southern Pacific countries at less than 8 hours. However, they may not be so deeply affected to this region.

The time series of water level at each city computed with models SO, SN and SS are shown in figure 7. The differences of each model are almost none. It shows that the uncertainty of tsunami model dose not effect in the southwestern Pacific Ocean. The water levels are very small at some cities in western half area of this region such as San Vicente and Biak. The Sanriku Tsunami may do no damage to this area. However, in the eastern half area, the water levels at some cities such as Micronesia and Marshall Island become several ten centimeters. Then, the hazard assessment for the Sanriku Tsunami is recommended.

The time series of water level at each observation station with models SO, SN and SS are shown in figure 8. In the western half area such as T3 and D6, the water levels are very small and no tsunami damage is supposed there. On the 

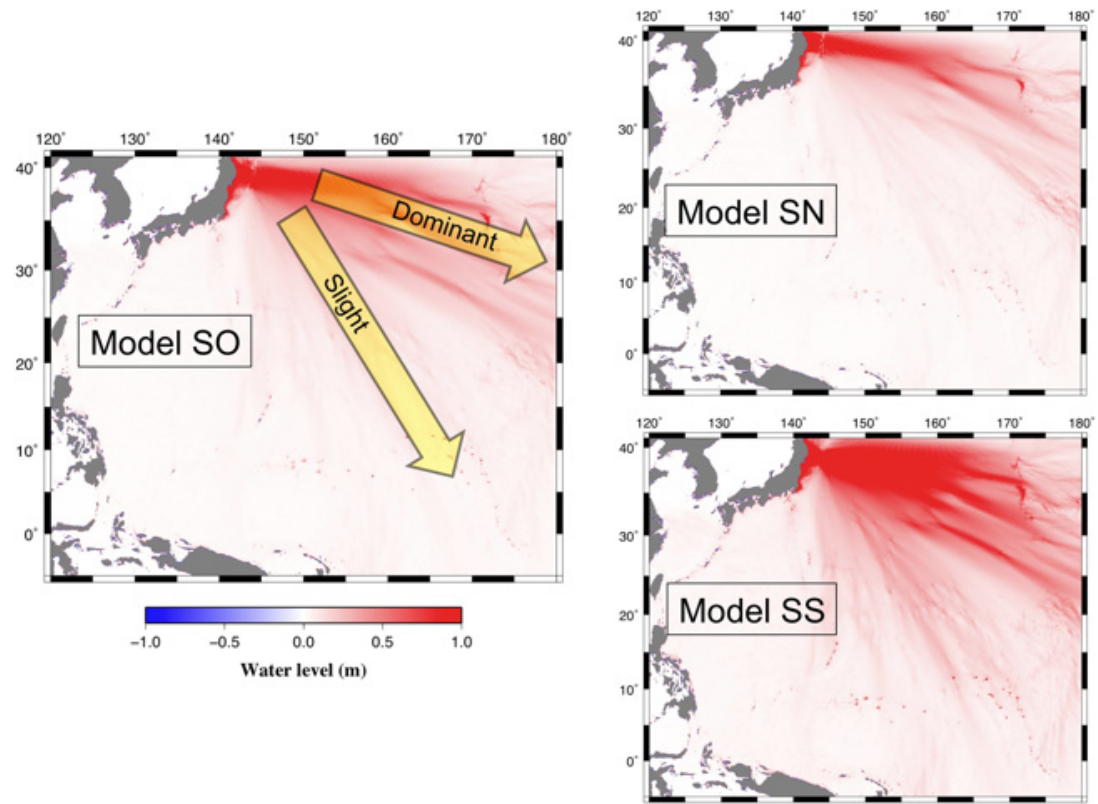

Figure 5: The computed tsunami energy distributions of models SO, SN and SE.
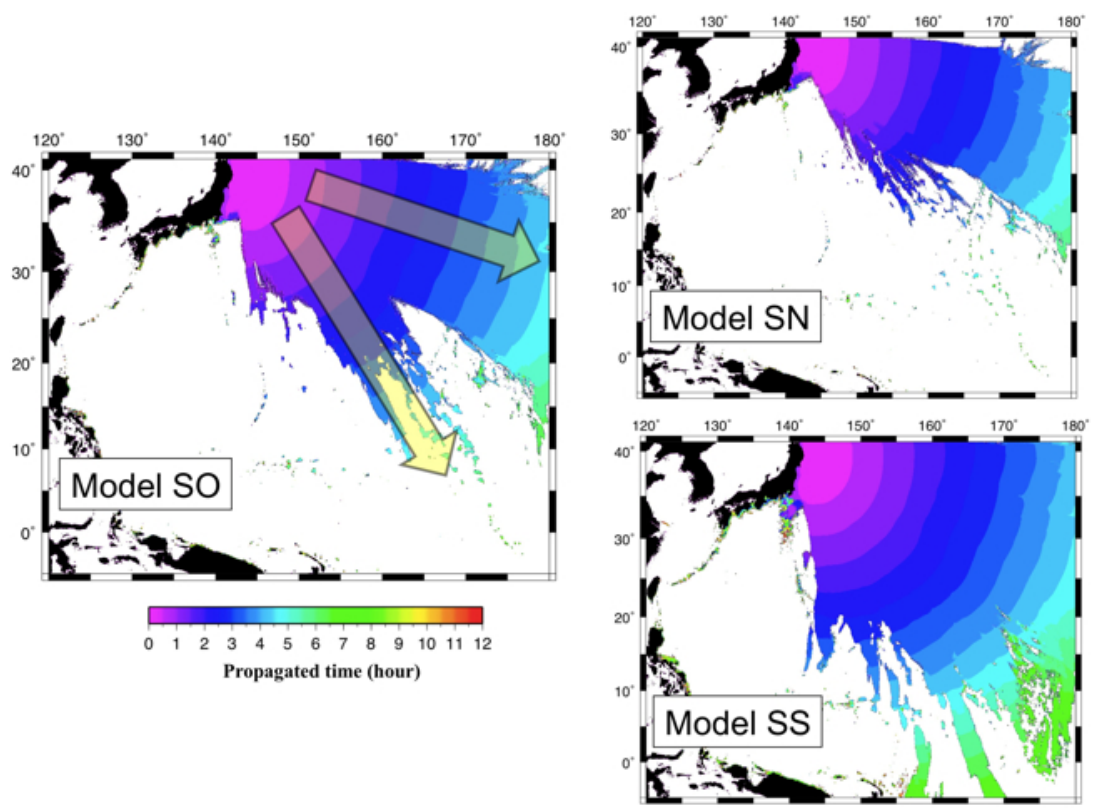

Figure 6: The computed propagation time distributions of models SO, SN and SE. 

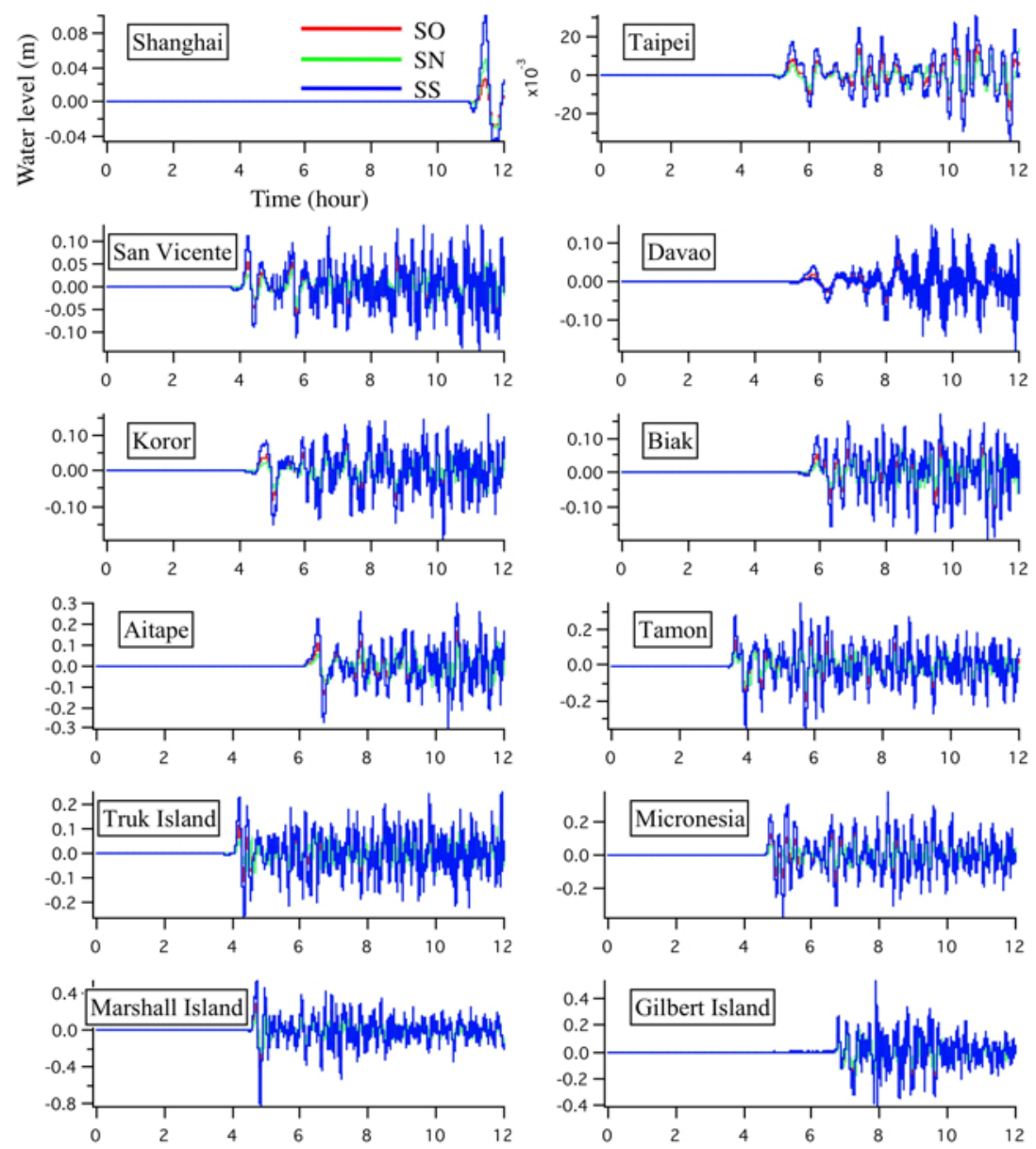

Figure 7: The time series of water level at each city by models $\mathrm{SO}, \mathrm{SN}$ and SS.

other hand, the eastern half area is recommended to establish a tsunami warning system and some observation stations are useful to the system. Because D1 is close to the Sanriku Tsunami source and D2 is located in the second propagating direction, they can be used to detect the tsunami generation and propagation toward this area. The observed data of the two observation stations may be utilized for the far field tsunami warning system in this area.

\subsection{The Tonankai-Nankai Earthquake Tsunami}

The computed tsunami energy distributions and propagation time distributions of models NO, NE and NW are shown in figures 9 and 10. The tsunamis in the Nankai Trough propagate in various directions compared with the Sanriku Tsunamis. However, much energy propagates toward the southwestern Pacific 

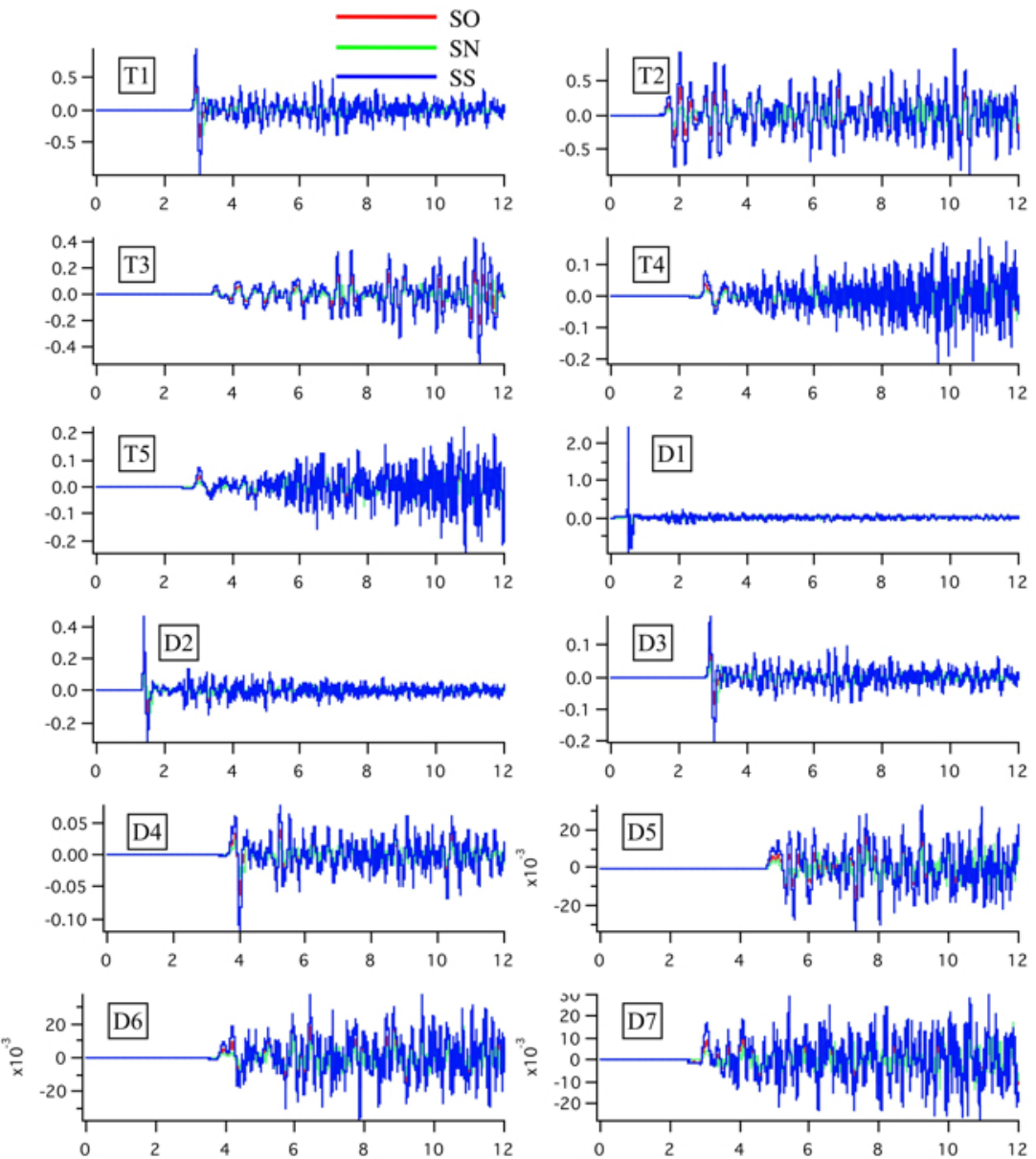

Figure 8: The time series of water level at observation stations by models $\mathrm{SO}, \mathrm{SN}$ and SS.

countries because of the Mariana Trench and this direction is prominent. The tsunamis arrive in this region at less than 6 hours, because they propagate in deep sea.

The time series of water level at each city computed with models NO, NE and NW are shown in figure 11. The differences of each model become larger than the Sanriku Tsunamis, but it is negligible. Because the tsunamis generated near Japan propagate on long distances, an effect of difference of tsunami source profiles may disappear. Then, location and magnitude of tsunami source become dominant parameters in this region. In many cities, the water levels exceed 50 centimeters and the hazard assessment for the Tonankai-Nankai Earthquake Tsunami is required there. 

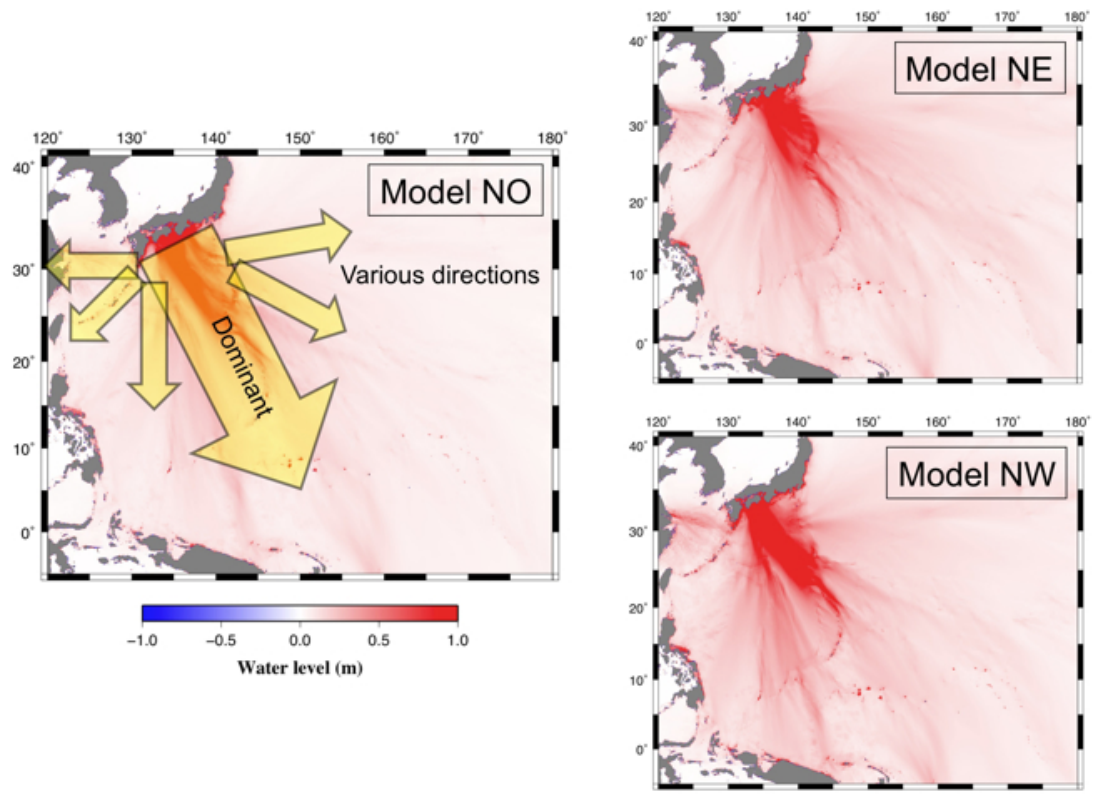

Figure 9: The computed tsunami energy distributions of models NO, NE and NW.

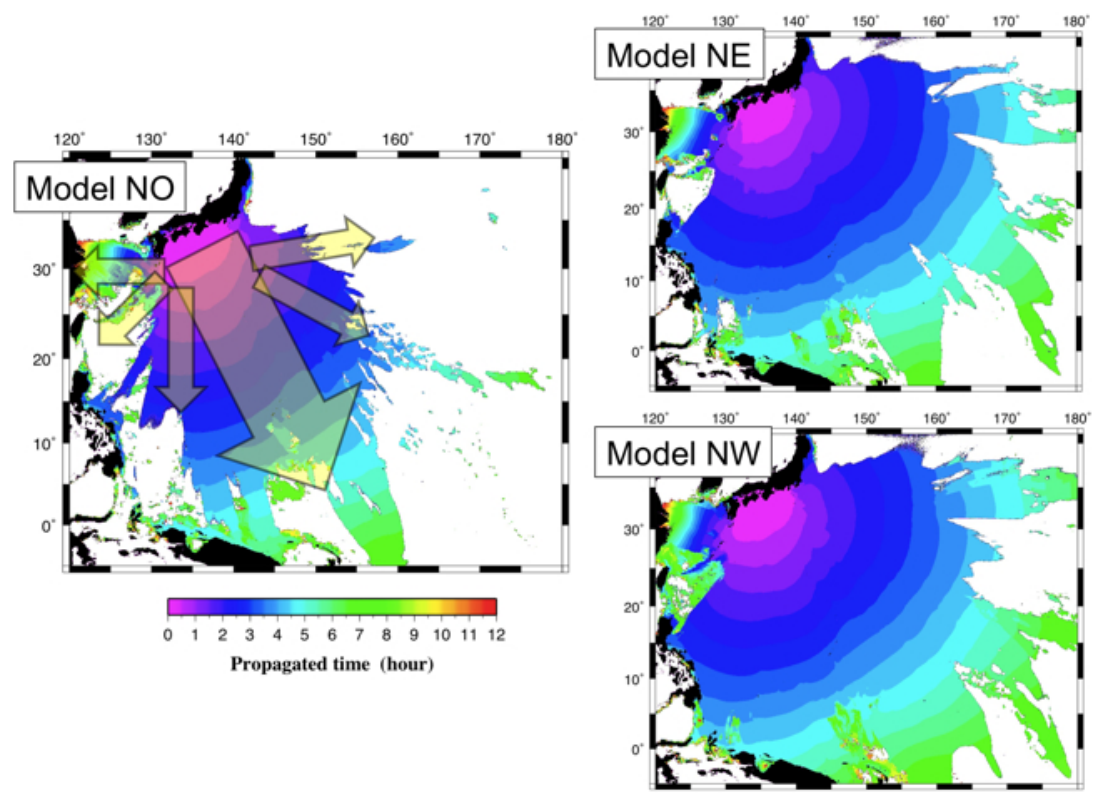

Figure 10: The computed propagation time distributions of models NO, NE and NW. 

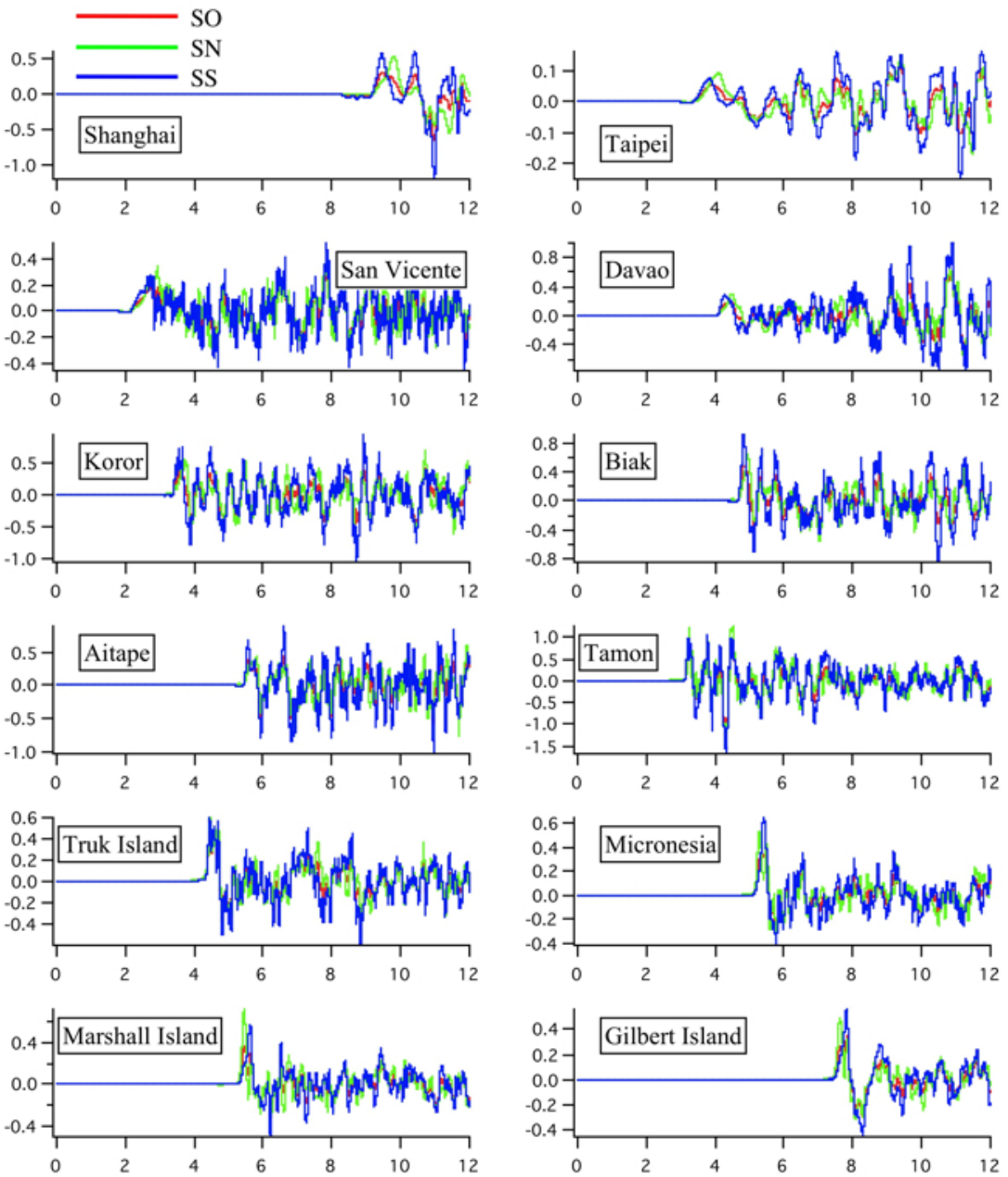

Figure 11: The time series of the water level at each city by models NO, NE and NW.

The time series of water level at each observation station with models NO, NE and NW are shown in figure 12. The data at observation stations are useful to the far field tsunami warning system from the Nankai Trough. Especially, T5 is close to tsunami source and it is located in the main propagating direction, then the observed data at T5 can be used to check tsunami generation in the Nankai Trough. In addition, if tsunamis are observed at D2, D3, D4 and D5 successively, and significant wave is observed at D5, high tsunami risk in the southwestern Pacific countries must be indicated. Then, the far field tsunami warning system in this region can utilize these observation stations. 

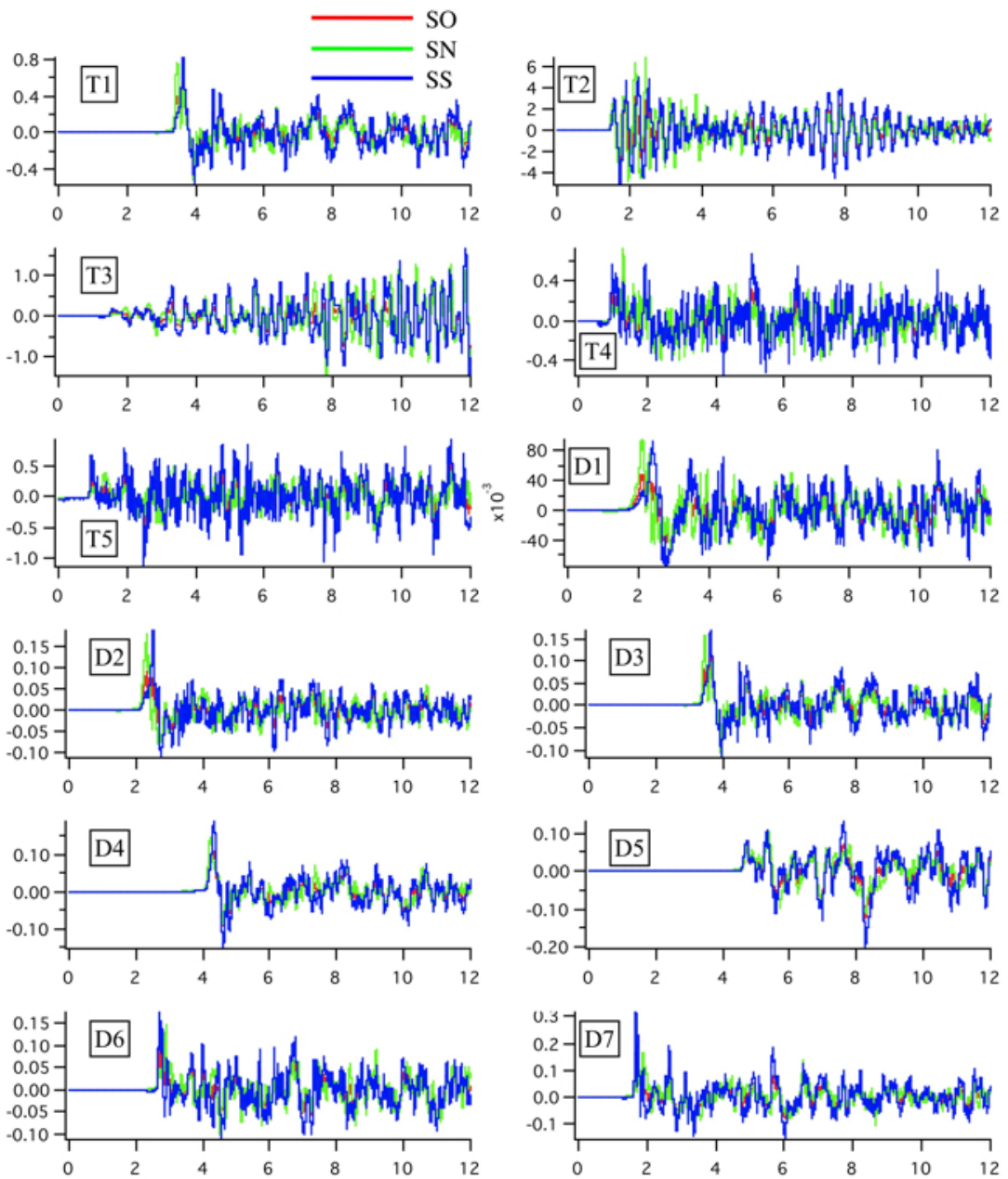

Figure 12: The time series of the water level at observation stations by models NO, NE and NW.

\section{Summary}

The numerical experiment on the giant tsunamis generated near Japan was conducted. The computed results show the tsunami risk and utilization of observation system in the southwestern Pacific Ocean.

Sanriku Tsunamis propagate in two directions on the Pacific Ocean. The tsunami energy toward the central Pacific Ocean is dominant and toward to the southwestern is slight comparatively. However, at some cities in the southwestern Pacific countries, the tsunamis become large and the hazard assessment is recommended. For the far field tsunami warning system, D1 and D2 are useful to check the tsunami generation and propagation. 
Tsunamis in the Nankai Trough propagate in various directions on the Pacific Ocean. Among them, the direction toward the southwestern Pacific Ocean is dominant. In many cities in this region, the tsunamis become large and hazard assessments are necessary. For tsunamis in the Nankai Trough, T5 is very useful to check tsunami generation. Furthermore, D2, D3, D4 and D5 can provide much information about the tsunami risk in the southwestern Pacific countries. These observed data can be utilized for the far field tsunami warning system in this region.

\section{References}

[1] Imamura, F. and Shuto, N., Numerical simulation of propagation of far-field tsunamis, Tohoku University, 11p., 1992.

[2] Monahan, D., GEBCO and Deep Water: data assembler, converter, interpreter and disseminator. Hydro International, 11(3), pp.7-9, 2007.

[3] Meinig, C., Stalin, S.E., Nakamura, A.I., Gonzalez, F. and Milburn, H.B, Technology developments in real-time tsunami measuring, monitoring and forecasting, OCEANS, 2005. Proceedings of MTS/IEEE, 2, pp.1673-1679, 2005.

[4] Central Disaster Management Council, Report of Organization for Technical Investigation on Subduction Zone Earthquakes in the Japan Trench and the Chishima Trench (in Japanese), 2006.

[5] Central Disaster Management Council, Report of Organization for Technical Investigation on Tonankai and Nankai Earthquakes (in Japanese), 2003. 